\title{
BMJ Open Individual and contextual factors associated with maternal healthcare utilisation in Mali: a cross-sectional study using Demographic and Health Survey data
}

\author{
Luchuo Engelbert Bain, ${ }^{1,2}$ Richard Gyan Aboagye (D) , ${ }^{3}$ Gift Malunga, ${ }^{4}$ \\ Hubert Amu (D) , ${ }^{5}$ Robert Kokou Dowou, ${ }^{3}$ Farrukh Ishaque Saah (D) ,,3 \\ Eugene Justine Kongnyuy ${ }^{6}$
}

To cite: Bain LE, Aboagye RG, Malunga $\mathrm{G}$, et al. Individual and contextual factors associated with maternal healthcare utilisation in Mali: a cross-sectional study using Demographic and Health Survey data. BMJ Open 2022;12:e057681. doi:10.1136/ bmjopen-2021-057681

- Prepublication history and additional supplemental material for this paper are available online. To view these files, please visit the journal online (http://dx.doi.org/10.1136/ bmjopen-2021-057681).

Received 26 September 2021 Accepted 28 January 2022

Check for updates

(c) Author(s) (or their employer(s)) 2022. Re-use permitted under CC BY-NC. No commercial re-use. See rights and permissions. Published by BMJ.

For numbered affiliations see end of article.

Correspondence to Dr Farrukh Ishaque Saah; fsaahpnur14@uhas.edu.gh

\section{ABSTRACT}

Objective We examined the national prevalence as well as the individual and contextual factors associated with maternal healthcare utilisation in Mali.

Setting The study was conducted in Mali.

Participants We analysed data on 6335 women aged 15-49 years from Mali's 2018 Demographic and Health Survey.

Outcome variable Maternal healthcare utilisation comprising antenatal care (ANC) attendant, skilled birth attendant (SBA), and postnatal care (PNC) attendant, was our outcome variable.

Results Prevalence of maternal healthcare utilisation was $45.6 \%$ for ANC4+, $74.7 \%$ for SBA and $25.5 \%$ for PNC. At the individual level, ANC4 + and SBA utilisation increased with increasing maternal age, level of formal education and wealth status. Higher odds of ANC4 + was found among women who are cohabiting (adjusted $\mathrm{OR}(\mathrm{aOR})=2.25,95 \% \mathrm{Cl} 1.16$ to 4.37$)$ and delivered by caesarean section (aOR=2.53, 95\% $\mathrm{Cl} 1.72$ to 3.73 ), while women who considered getting money for treatment (aOR=0.72, 95\% Cl 0.60 to 0.88) and distance to health facility (aOR=0.73, $95 \% \mathrm{Cl} 0.59$ to 0.90$)$ as a big problem had lower odds. Odds to use PNC was higher for those who were working ( $\mathrm{a} 0 \mathrm{R}=1.22,95 \% \mathrm{Cl} 1.01$ to 1.48$)$ and those covered by health insurance $(\mathrm{aOR}=1.87,95 \% \mathrm{Cl}$ 1.36 to 2.57). Lower odds of SBA use were associated with having two (aOR=0.48,95\% $\mathrm{Cl} 0.33$ to 0.71$)$, three (a0R $=0.37,95 \% \mathrm{Cl} 0.24$ to 0.58 ), and four or more (aOR=0.38, 95\% $\mathrm{Cl} 0.24$ to 0.59 ) children, and residing in a rural area (aOR=0.35, 95\% $\mathrm{Cl} 0.17$ to 1.69$)$. Listening to the radio and watching $\mathrm{TV}$ were associated with increased maternal healthcare utilisation.

Conclusion The government should increase availability, affordability and accessibility to healthcare facilities by investing in health infrastructure and workforce to achieve Sustainable Development Goal 3.4 of reducing maternal morality to less than 70 deaths per 100000 live births by 2030. It is important to ascertain empirically why PNC levels are astonishingly lower relative to ANC and SBA.
Strengths and limitations of this study

- The strength of the study is the use of national-level data and use of logistic regression models to analyse the associations between variables.

- A major limitation of the study is the use of secondary data from the Demographic and Health Survey.

- Even though we used national-level data and the results were strong enough, we did not have any control over cleaning and ensuring internal consistencies of the data.

- The data relied on verbal reports from participants which could suffer from recall bias.

\section{INTRODUCTION}

More than 810 women die globally from pregnancy and childbirth-related complications every day. ${ }^{1}$ Complications during pregnancy and childbirth constitute the second leading cause of death among women. ${ }^{2-4}$ Approximately more than $94 \%$ of all daily maternal deaths occur in low-income and lower-middle-income countries. ${ }^{1}$ In 2017, nearly 196000 women of reproductive age died during childbirth. ${ }^{4}$

The global agenda of Sustainable Development Goal (SDG) 3 (ensure healthy lives and promote well-being for all at all ages) targets 3.1 and 3.2, to which all low-income and middle-income countries (LMICs) are major signatories, in general aims at reducing global maternal mortality ratio to less than 70 per 100000 live births, and neonatal mortality to at least 12 per 1000 live births and underfive mortality to at least 25 per 1000 live births, respectively, by $2030 .^{5}$ The Maternal and Child Health Index constitutes the foremost indicator for assessing the reliance and the performance of health systems of every 
country. ${ }^{6}$ Nevertheless, maternal and neonatal mortality remains a significant public health problem clogging the progress of sub-Saharan Africa (SSA) towards having a stable health system and achieving SDGs. ${ }^{7}$ The WHO estimated that out of the $99 \%$ of all maternal deaths occurring in LMICs, more than half occur in SSA. ${ }^{89}$ The WHO also acknowledged that young women (10-14 years) face a higher risk of complications and death as a result of pregnancy than older women. ${ }^{1}$

Limited financial capacity in paying for maternal health is one of the key barriers to utilisation of maternal and newborn healthcare services. The fear of paying for excessive expenses, for instance, deters or delays some women's decision to seek care even while dealing with obstetric complications. ${ }^{10}$ Nevertheless, health insurance has been identified to limit or remove this barrier in many studies in developing countries. ${ }^{11-13}$

Mali remains among the many countries in the subregion where maternal mortality remains relatively high. Mali's maternal mortality ratio is estimated to be as high as 562 deaths per 100000 live births. ${ }^{414}$ More than $80 \%$ of these women's deaths in Mali are preventable. ${ }^{15}$ This high maternal mortality ratio, however, comes at the backdrop of various interventions implemented by the government to ameliorate the status quo. ${ }^{16-19}$ For instance, in efforts to improve access to maternal healthcare service, Mali, on 1 January 2005, introduced a fee exemption policy for C-sections which covered the cost of all C-sections including the surgical procedure and preoperative assessments, the surgical kit and postoperative treatment, and hospitalisation in public and private health facilities. ${ }^{20}{ }^{21}$ Also, since 2019, the Malian government has initiated a series of policies to reform national healthcare, expected to fully be in effect by $2022 .{ }^{22}{ }^{23}$ Among these is the removal of point-of-service fees for healthcare for vulnerable populations namely pregnant women and children under 5 years. ${ }^{23}$

Poor maternal healthcare utilisation comprising late initiation/non-attendance of antenatal care (ANC) during pregnancy, births not being assisted by a skilled birth attendant (SBA) and poor postnatal care (PNC) are identified as major factors resulting in high maternal deaths. ${ }^{16192425}$ Skilled health service care before, during and after childbirth can save the lives of women and their newborns. ${ }^{1}$

The ambitious SDG agenda may not be achieved in many SSA countries including Mali ${ }^{5}$ if the utilisation of maternal healthcare components such as ANC, SBA and PNC is not accelerated. ${ }^{26}$ There is, however, a paucity of empirical literature on the state of maternal healthcare utilisation (ANC, SBA and PNC) at the national level in the country. Such data are needed for the acceleration of interventions to improve utilisation, reduce maternal mortality and accelerate progress towards achievement of the SDGs. Our study, therefore, examined the prevalence as well as the individual and contextual factors associated with maternal healthcare utilisation in Mali using the most recent (2018) and nationally representative
Demographic and Health Survey (DHS) data. The findings from this study could serve as the scientific basis on which policy makers and programme planners base interventions seeking to promote maternal healthcare utilisation towards reducing maternal mortality in Mali.

\section{METHODS}

\section{Data source and study design}

We analysed a cross-sectional data from the 2018 DHS of Mali. The DHS is a nationally representative and comparative survey conducted in over 85 LMICs worldwide. ${ }^{27} \mathrm{~A}$ structured questionnaire was used to collect data from the respondents on health indicators such as maternal healthcare utilisation. ${ }^{27}$ The respondents were sampled using a two-stage cluster sampling technique. Detailed sampling technique has been highlighted in a study by Aliaga and Ruilin. ${ }^{28}$ In the present study, a total of 6335 women of reproductive age (15-49 years) were included in the analysis. The data set is freely available for download on the DHS platform. ${ }^{29}$ In drafting this manuscript, we relied on the Strengthening the Reporting of Observational Studies in Epidemiology statement guidelines. ${ }^{30}$

\section{Study setting}

Mali is a West-African country with a population of 20548 $743 .{ }^{31}$ It has a pyramidal healthcare system, the community health system, requiring entry into the health system from community health centres. ${ }^{32}$ This decentralised system operates at five levels, namely national, regional, district, health area and community. ${ }^{32}$ The major healthcare financing mechanism is out-of-pocket payments for services including maternal healthcare services. Existing insecurities and internal displacement of people have also exacerbated inequalities in health infrastructure and access. $^{33}$

\section{Patient and public involvement}

No patients were involved in this study as we used secondary data.

\section{Variables}

Outcome variables

ANC, SBA and PNC were the outcome variables in this study. To assess ANC, the respondents were asked about the number of antenatal visits they made during their recent pregnancy. The response options recoded into $0-3=0$ ( $<4$ ANC attendance) and $\geq 4=1 \quad(\geq 4$ ANC attendance). With SBA, the respondents were asked 'Who assisted (NAME) during delivery?'. Those whose response options included any category of health professionals were classified as 'having SBA' while those who were assisted by traditional birth attendants and others were grouped as 'not having SBA'. PNC on the other hand was assessed using the question, 'Did (NAME) go for postnatal checks within 2 months?'. The response options were $0=$ no; $1=y e s ;$ and $8=$ don't know. Those whose response option was 'don't know' were dropped. We, therefore, used the 
dichotomised responses in the final analysis. The coding and classification were informed by literature that used the DHS data sets. ${ }^{34-37}$

\section{Explanatory variables}

We considered 17 explanatory variables in this study. These variables were selected based on their availability in the DHS data sets as well as their significant association with the outcome variables in the study. ${ }^{34} 3839$ The variables were ground into individual level (age of the respondent, educational level, marital status, religion, current working status, parity, national health insurance coverage, delivery by caesarean section, frequency of listening to radio, frequency of watching television, frequency of reading newspaper or magazine, getting medical help for self: permission to go; getting medical help for self: distance to health facility, and getting medical help for self: getting money for treatment) and contextual level (wealth index, place of residence and region). We maintained the existing coding in the DHS data set for current working status, national health insurance, delivery by caesarean section, frequency of listening to radio, frequency of watching television, frequency of reading newspaper/magazine, getting medical help for self: permission to go; getting medical help for self: distance to health facility, and getting medical help for self: getting money for treatment, wealth index, place of residence and region. The age of the respondent was recoded into '15-19', '20-24', '25-29', '30-34' and '35 and above'. The level of education of the respondent was recoded into 'no education', 'primary' and 'secondary or higher'. Marital status was coded as 'never married', 'married', 'cohabiting' and 'widowed or divorced or separated'. Religious affiliation was coded as 'Christianity', 'Islamic', 'African Traditional or no religion or others'. Parity was coded as 'one birth', 'two births', 'three births' and 'four or more births'.

\section{Statistical analyses}

Stata software V.16.0 was used to perform the statistical analysis. All the analyses were weighted. We used percentages to summarise the prevalence of ANC, SBA and PNC as shown in figure 1. Later, cross-tabulation and $\chi^{2}$ tests were performed to examine the distribution of the outcome variables across the explanatory variables. Corresponding $\mathrm{p}$ values from the $\chi^{2}$ test were used to determine the statistically significant association between the outcome variables and the explanatory variables. All the variables that showed significance were placed in the regression model. We built four models under multilevel regression analysis to examine the association between each of the outcome variables and the explanatory variables. The first model (Model O) was fitted to show the variance in the outcome variables attributed to the clustering of the primary sampling units and the explanatory variables. Model I was fitted to include the individual-level variables against each of the outcome variables. Model II contained the contextual-level variables. Model III was

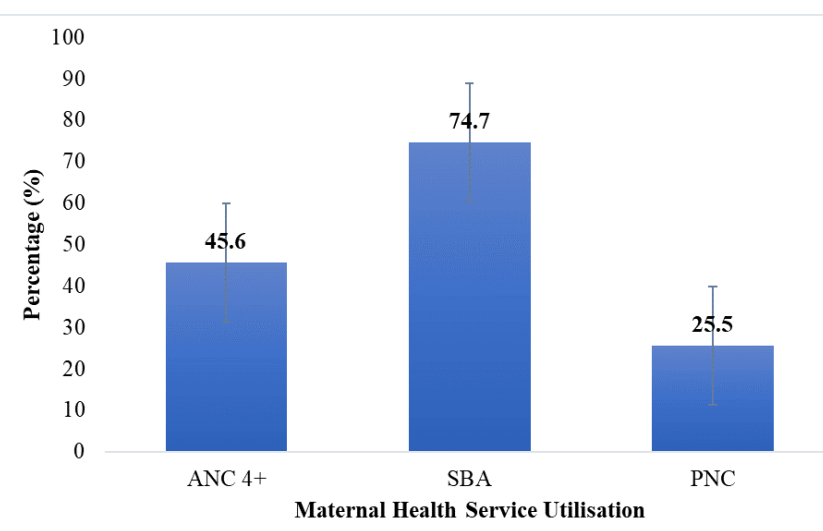

Figure 1 Prevalence of maternal healthcare utilisation among women in Mali. ANC, antenatal care; PNC, postnatal care; SBA, skilled birth attendant.

fitted to include all the explanatory variables against each of the outcome variables. We used Akaike's Information Criterion to test for model fitness and model comparison. The result of the regression analysis was presented using adjusted ORs (aORs) with their 95\% CIs. We applied the women's sample weights (v005/1000 000) to obtain unbiased estimates, according to the DHS guidelines and the Stata survey command 'svy' was used to adjust for the complex sampling structure of the data in all the analyses.

\section{Ethical considerations}

Since our analysis was based on publicly available data, no further ethical permission was necessary. Ethical guidelines regarding the usage of secondary data for publication were adhered to. Further information about DHS data usage and ethical standards are available at http:// googl/ny8T6X.

\section{RESULTS \\ Prevalence of maternal healthcare utilisation among women in Mali}

Results from the descriptive analysis in figure 1 show that the prevalence of various maternal healthcare components among women in Mali were $45.6 \%$ (95\% CI $44.4 \%$ to $46.8 \%$ ) for ANC, $74.7 \%$ (95\% CI $73.6 \%$ to $75.8 \%$ ) for SBA and $25.5 \%$ (95\% CI $24.4 \%$ to $26.6 \%$ ) for PNC.

\section{Bivariable relationship between maternal healthcare utilisation and the explanatory variables}

Table 1 presents bivariable analyses of predictors of ANC, SBA and PNC among women in Mali. We found that educational level, ownership of health insurance, delivery by caesarean section, exposure to mass media, wealth, place of residence and region of women were significantly related to ANC, SBA and PNC utilisation. Parity and getting medical help for self (permission to go, getting money for treatment and distance to the health facility) were significantly related to ANC and SBA utilisation among women. Religion was significantly related to ANC and PNC. Marital status and maternal current 
Open access

Table 1 Bivariate analysis of predictors of ANC, SBA and PNC among women in Mali $(n=6335)$

\begin{tabular}{|c|c|c|c|c|c|c|}
\hline \multirow[b]{2}{*}{ Variables } & \multicolumn{2}{|c|}{ ANC 4+ } & \multicolumn{2}{|l|}{ SBA } & \multicolumn{2}{|l|}{ PNC } \\
\hline & Yes & $P$ value & Yes & $P$ value & Yes & $P$ value \\
\hline Maternal age (years) & & 0.531 & & 0.315 & & 0.722 \\
\hline $15-19$ & 43.6 & & 77.2 & & 27.0 & \\
\hline 20-24 & 46.5 & & 76.3 & & 24.1 & \\
\hline $25-29$ & 44.2 & & 74.2 & & 25.1 & \\
\hline $30-34$ & 46.9 & & 74.6 & & 25.8 & \\
\hline $35+$ & 46.1 & & 73.1 & & 26.2 & \\
\hline Educational level & & $<0.001$ & & $<0.001$ & & 0.024 \\
\hline No education & 38.5 & & 68.5 & & 24.3 & \\
\hline Primary & 52.6 & & 84.2 & & 28.3 & \\
\hline Secondary/higher & 41.8 & & 95.4 & & 28.8 & \\
\hline Marital status & & 0.467 & & 0.008 & & 0.546 \\
\hline Never married & 50.9 & & 87.8 & & 31.4 & \\
\hline Married & 45.5 & & 74.3 & & 25.3 & \\
\hline Cohabiting & 36.1 & & 83.5 & & 29.4 & \\
\hline Widowed/divorced/separated & 48.2 & & 73.7 & & 27.7 & \\
\hline Religion & & 0.003 & & 0.065 & & 0.005 \\
\hline Christianity & 46.8 & & 73.3 & & 30.8 & \\
\hline Islamic & 46.2 & & 75.3 & & 25.8 & \\
\hline African traditional/no religion/others & 30.3 & & 62.8 & & 13.3 & \\
\hline Current working status & & 0.922 & & 0.078 & & 0.027 \\
\hline No & 45.5 & & 72.7 & & 23.2 & \\
\hline Yes & 45.7 & & 76.3 & & 27.2 & \\
\hline Parity & & $<0.001$ & & $<0.001$ & & 0.108 \\
\hline 1 & 51.2 & & 84.3 & & 28.9 & \\
\hline 2 & 47.5 & & 76.5 & & 24.2 & \\
\hline 3 & 48.4 & & 74.9 & & 25.9 & \\
\hline 4 or more & 42.3 & & 71.0 & & 24.6 & \\
\hline National health insurance & & $<0.001$ & & 0.003 & & $<0.001$ \\
\hline No & 43.9 & & 73.8 & & 24.3 & \\
\hline Yes & 79.2 & & 93.8 & & 48.8 & \\
\hline Delivery by caesarean section & & $<0.001$ & & $<0.001$ & & 0.042 \\
\hline No & 44.7 & & 74.0 & & 25.3 & \\
\hline Yes & 73.1 & & 99.5 & & 32.2 & \\
\hline Frequency of reading newspaper/magazine & & $<0.001$ & & $<0.001$ & & 0.039 \\
\hline Not at all & 43.8 & & 73.5 & & 25.1 & \\
\hline Less than once a week & 79.0 & & 98.1 & & 31.2 & \\
\hline At least once a week & 77.8 & & 96.3 & & 36.3 & \\
\hline Frequency of listening to radio & & $<0.001$ & & $<0.001$ & & $<0.001$ \\
\hline Not at all & 35.5 & & 66.3 & & 20.2 & \\
\hline Less than once a week & 45.0 & & 73.2 & & 26.9 & \\
\hline At least once a week & 52.7 & & 81.2 & & 28.4 & \\
\hline Frequency of watching television & & $<0.001$ & & $<0.001$ & & $<0.001$ \\
\hline Not at all & 32.2 & & 61.0 & & 20.9 & \\
\hline Less than once a week & 44.8 & & 77.4 & & 27.8 & \\
\hline
\end{tabular}

Continued 
Table 1 Continued

\begin{tabular}{|c|c|c|c|c|c|c|}
\hline \multirow[b]{2}{*}{ Variables } & \multicolumn{2}{|c|}{ ANC 4+ } & \multicolumn{2}{|l|}{ SBA } & \multicolumn{2}{|l|}{ PNC } \\
\hline & Yes & P value & Yes & P value & Yes & P value \\
\hline At least once a week & 59.0 & & 86.7 & & 28.6 & \\
\hline Not a big problem & 48.9 & & 78.7 & & 26.4 & \\
\hline Big problem & 37.4 & & 65.1 & & 23.3 & \\
\hline Not a big problem & 51.9 & & 82.1 & & 25.3 & \\
\hline Big problem & 30.9 & & 57.5 & & 26.0 & \\
\hline Getting medical help for self: Getting money for treatment & & $<0.001$ & & $<0.001$ & & 0.080 \\
\hline Not a big problem & 53.1 & & 81.7 & & 26.7 & \\
\hline Poorer & 32.7 & & 61.8 & & 22.0 & \\
\hline Middle & 38.9 & & 71.0 & & 19.2 & \\
\hline Richer & 54.1 & & 88.9 & & 22.8 & \\
\hline Richest & 77.8 & & 97.4 & & 34.1 & \\
\hline Place of residence & & $<0.001$ & & $<0.001$ & & $<0.001$ \\
\hline Urban & 71.7 & & 94.6 & & 32.9 & \\
\hline Rural & 38.4 & & 69.2 & & 23.4 & \\
\hline Region & & $<0.001$ & & $<0.001$ & & $<0.001$ \\
\hline Kayes & 45.1 & & 63.0 & & 23.2 & \\
\hline Kidal & 10.6 & & 26.0 & & 38.3 & \\
\hline Bamako & 77.9 & & 97.7 & & 36.4 & \\
\hline
\end{tabular}

${ }^{*} \mathrm{P}$ values obtained from $\chi^{2}$ test.

ANC, antenatal care; PNC, postnatal care; SBA, skilled birth attendant.

working status were only significantly related to SBA and PNC utilisation, respectively.

Multilevel logistic regression analyses on the individual and contextual factors associated maternal healthcare utilisation among women in Mali

Online supplemental table 1 presents the mixed-effect analysis of predictors of ANC4 + (having four or more ANC visits) among women in Mali. We found that ANC4 + utilisation increased with increasing maternal age, level of formal education, parity and wealth status. Women aged $30-34$ years $(\mathrm{aOR}=1.63,95 \%$ CI 1.17 to 1.69$)$ and those aged $35+$ years $(\mathrm{aOR}=1.78,95 \%$ CI 1.30 to 2.43$)$ had higher odds of using ANC4 + compared with those aged 15-19 years. Also, women with primary education and those with secondary or higher level of formal education were, for instance, 1.37 times (95\% CI 1.1.12 to 1.69) and 1.86 times (95\% CI 1.48 to 2.33 ), respectively, more likely to use ANC4 + than those with no formal education. Women who were cohabiting had 2.25 (95\% CI 1.16 to 4.37) higher odds of using ANC4 + than those who were never married. Those who had four or more children had lower odds of using ANC4+ $(\mathrm{aOR}=0.75,95 \%$ CI 0.57 to 1.00 ) than those who were primiparous, and women in the richer and richest wealth quintile were 1.63 times (95\% CI 1.23 to 2.16 ) and 2.3 times (95\% CI 1.57 to 3.35 ), respectively, more likely to use ANC4 + than the poorest women. Women who were delivered by caesarean section $(\mathrm{aOR}=2.53,95 \%$ CI 1.72 to 3.73$)$ were more likely to use 
ANC4 + than those who did not deliver by caesarean section. Respondents who were exposed to newspaper/ magazine less than once a week (aOR=1.49, 95\% CI 1.01 to 2.21 ), radio (aOR=1.25, 95\% CI 1.06 to 1.48 ) and television (aOR=1.37, 95\% CI 1.12 to 1.68 ) also had higher odds of using ANC4 + than those who were not exposed. With regard to getting medical help for self, women who considered getting money for treatment $(\mathrm{aOR}=0.72$, $95 \%$ CI 0.60 to 0.88 ) and the distance to health facility $(\mathrm{aOR}=0.73,95 \%$ CI 0.59 to 0.90$)$ as a big problem were less likely to use ANC4 +, respectively. Concerning region of residence, women in Sikasso $(\mathrm{aOR}=0.58,95 \%$ CI $0.42,0.81$ ), Toumbouctou ( $\mathrm{aOR}=0.61,95 \%$ CI 0.38 to 0.99 ) and Kidal (aOR=0.10, 95\% CI 0.05 to 0.22 ) were less likely to use ANC4 + than those in Kayes. However, women in Bamako (aOR=1.56, 95\% CI 1.04 to 2.35) had higher odds of using ANC4 + than those in Kayes.

Online supplemental table 2 presents the mixedeffect analyses on the predictors of SBA among women in Mali. We found that SBA utilisation increased with maternal age, level of formal education and wealth status. Compared with women aged 15-19 years, those aged 25-29 years $(\mathrm{aOR}=1.73,95 \%$ CI 1.13 to 2.64$), 30-34$ years $(\mathrm{aOR}=1.10 .67,95 \%$ CI 1.03 to 2.70$)$ and $35+$ years (aOR $=1.95,95 \%$ CI 1.23 to 3.08) have higher odds of using SBA. Women with primary $(\mathrm{aOR}=1.82,95 \%$ CI 1.36 to 2.44) and secondary or higher formal $(\mathrm{aOR}=2.17,95 \% \mathrm{CI}$ 1.40 to 3.35 ) education were more likely to use SBA than those with no formal education. Women in the middle $(\mathrm{aOR}=1.33,95 \%$ CI 1.04 to 1.70$)$, richer $(\mathrm{aOR}=3.01,95 \%$ CI 1.91 to 4.76$)$, and richest $(\mathrm{aOR}=7.79,95 \%$ CI 3.20 to 18.95 ) wealth quintiles had a higher probability of using SBA than the poorest women. Additionally, compared with primiparous women, those with two $(\mathrm{aOR}=0.48,95 \%$ CI 0.33 to 0.71 ), three ( $\mathrm{aOR}=0.37,95 \%$ CI 0.24 to 0.58 ) and four or more ( $\mathrm{aOR}=0.38,95 \%$ CI 0.24 to 0.59 ) children had lower odds of using SBA. The probability of using SBA declined with parity. The odds of SBA utilisation was higher for women who delivered by caesarean section $(\mathrm{aOR}=85.83,95 \%$ CI 8.93 to 824.86 ) compared with those who did not. Women who watched television at least once a week were 1.43 times (95\% CI 1.12 to 1.81 ) more likely to use SBA than those who never watched. Rural dwellers (women) also had lower odds of using SBA $(\mathrm{aOR}=0.35$, $95 \%$ CI 0.17 to 1.69 ) than urban women. Compared with women in Kayes region, those in Koulikoro $(\mathrm{aOR}=5.30$, 95\% CI 2.51 to 11.17 ), Sikasso (aOR $=5.34,95 \%$ CI 2.75 to 10.36$)$ and Bamako (aOR=4.75, 95\% CI 1.82 to 12.41$)$ regions had higher odds of using SBA while those in Toumbouctou (aOR $=0.40,95 \%$ CI 0.18 to 0.88 ) and Kidal (aOR $=0.03,95 \%$ CI 0.01 to 0.08 ) regions had lower odds of using SBA.

Online supplemental table 3 presents the mixed-effect analyses of predictors of PNC among women in Mali. We found that women who were working were 1.22 times (95\% CI 1.01 to 1.48 ) more likely to use PNC compared with those who were not working whereas those who were covered by health insurance were more likely to use PNC
(aOR=1.87, 95\% CI 1.36 to 2.57) than those who were not covered. Regarding mass media exposure, we found that women who reported listening to radio less than once a week ( $\mathrm{aOR}=1.42,95 \%$ CI 1.11 to 1.82$)$ and at least once a week ( $\mathrm{aOR}=1.41,95 \%$ CI 1.12 to 1.78 ) were more likely to use PNC than those who were not exposed. Again, those who watched television less than once a week $(\mathrm{aOR}=1.43$, 95\% CI 1.13 to 1.80) had higher odds of using PNC than those who did not watch. We also found that women from Mopti (aOR=4.14, 95\% CI 2.33 to 7.38), Kidal $(\mathrm{aOR}=2.32$, 95\% CI 1.23 to 4.38 ) and Bamako (aOR=1.98, 95\% CI 1.15 to 3.40) regions had higher odds of using PNC while those from Sikasso $(\mathrm{aOR}=0.40,95 \%$ CI 0.25 to 0.64$)$ had lower odds of using PNC compared women in Kayes.

\section{DISCUSSION}

This study examined the individual and contextual factors associated with maternal healthcare utilisation in Mali using DHS data. The overall prevalence of maternal healthcare utilisation was $45.6 \%$ for ANC4+, $74.7 \%$ for SBA and $25.5 \%$ for PNC which are higher than $(30 \%$ ANC4 + and 38\% SBA) those reported in the 2001 DHS. ${ }^{40}$ The prevalence of ANC4 + reported in this study is relatively lower than the $95.6 \%, 52.44 \%, 58.53 \%$ and $90.4 \%$ ANC4 + reported in other SSA countries. ${ }^{41-44}$ Again, the prevalence of PNC observed in this study is comparatively lower than that in studies in Ghana $(74 \%),{ }^{45}$ Ethiopia $(51.2 \%)^{46}$ and the pooled prevalence in SSA $(52.48 \%){ }^{47}$ The prevalence of SBA is higher than that of a previous study reporting $39.9 \%$ of SBA in Mali. ${ }^{48}$ The lower prevalence of ANC4 + reported in this study is worrying as the majority of maternal complications during delivery and deaths that occur in SSA are linked to poor utilisation of quality ANC as recommended. ${ }^{34}$ The observations regarding ANC and PNC utilisation come at the backdrop of expectation and the WHO recommendation that women should ideally attend ANC about four times (focused ANC) before delivery which is supervised by a skilled attendant, and then receive adequate PNC within 42 days after delivery. ${ }^{49}$ Focused ANC facilitates early detection of risk factors/potential complications and implementation of timely interventions. ${ }^{51}{ }^{52}$

This observation calls for imperative measures to be implemented by the health authorities in Mali to promote and improve women's utilisation of ANC four times before delivery. Successful maternal health programmes and interventions such as the United States Agency for International Development's (USAID) Maternal and Child Survival Program implemented by the government of Mali and its partners with the intent of achieving the global SDG 3.4 target considerably reducing maternal mortality to less than 70 deaths per 100000 live births by 2030 could explain the higher prevalence of SBA observed in this study. ${ }^{5} 485354$

Regarding the individual factors that influence maternal healthcare utilisation, we found in the current study that women with higher formal education have a 
higher probability of using maternal healthcare (ANC, SBA and PNC). This finding is consistent with the observations made by previous studies. ${ }^{55-57}$ The observation made in the study could be ascribed to the fact that educated women become more informed, conscious and knowledgeable about the importance of ANC4+, SBA and PNC for their health and that of their children. ${ }^{485-60}$ This implies that more education needs to be given to young girls and women, especially those from rural settings, by providing them with essential information on maternal healthcare, hence empowering them to make informed reproductive health decisions.

We realised in this study that women who are covered by national health insurance have higher odds of using at least four times ANC when pregnant, have their child delivery supervised by a SBA and then receive adequate PNC within 42 days after delivery. This finding is congruent with the findings of many previous studies which noted similar observations that health insurance use among pregnant women increases their use of ANC, skilled birth and postnatal care. ${ }^{61-63}$

The observation where health insurance coverage increases the probability of women using maternal healthcare could be explained by the fact that the possession of valid health insurance serves as a financial protection factor for women, hence relieving them of the predicament of out-of-pocket payment at the health facilities. Lack of health insurance prevents women, especially those from poor households, from seeking or accessing appropriate and adequate maternal healthcare especially during pregnancy and childbirth which is recognised as a major promoting factor of a significant proportion of the mortality in SSA. ${ }^{64-67}$ Owing to the importance of health coverage, many governments in SSA have implemented national health insurance policies as a way of increasing maternal healthcare and reducing maternal mortality. ${ }^{68}$

Individual factors revealed significant association between mass media exposure (radio, TV and newspapers) and maternal healthcare utilisation among women in Mali. We noted that women who use any form of social media as a source of information have higher likelihood of seeking maternal healthcare during pregnancy, delivery and after delivery. This outcome of our results is consistent with findings of previous studies that reported a significant association between maternal healthcare utilisation and mass media. ${ }^{69-72}$ This observation points to the importance and the crucial role mass media plays in creating health-seeking and utilisation awareness among women.$^{73-75}$ In Mali, like in many SSA countries, media-especially television and radio-are used in public health education and dissemination of health policy interventions.

Parity was realised to determine maternal healthcare utilisation by women in Mali. We found that women with four or more children have a lower probability of having their subsequent child through institutional delivery or by a qualified health attendant than women who were having their first birth. This finding is consistent with previous studies reporting that parity significantly influences women's decision to used skilled/supervised delivery. ${ }^{39} 76-79$ This may be due to the fact that women who have ever delivered in the past may have developed the self-confidence to deliver at home and may not be interested in using a health professional due to their experience and knowledge of earlier pregnancies. Also, women with many children who have used health facilities during the delivery of those children in the health facilities and are dissatisfied with the care and negative attitude experienced may not be motivated to use approved maternal healthcare again. ${ }^{39} 76-80$ The reason that could increase maternal healthcare utilisation among the primiparous women could be that they are giving birth for the first time and may lack experience from a prior delivery, and hence may be afraid, are more cautious and concerned about pregnancy complications and outcomes. ${ }^{39} 7981$

Regarding the contextual factors influencing maternal healthcare utilisation, we realised that the wealth status of women positively influences the use of maternal healthcare in Mali; this implies that wealthier women have more chance of attending ANC during their pregnancies, deliver in a health facility and continue with PNC after delivery, than poorer women. This finding corroborates suggestions made in previous studies which also indicated that as compared with women in the poorer households, women in the middle or higher wealth quintile have higher odds of using maternal healthcare (ANC, SBA and PNC).$^{61}{ }^{82-85}$ This comes at the backdrop that an estimated $60 \%$ of Mali's population live in rural areas with limited socioeconomic status and infrastructure and $49 \%$ of the population live below the national poverty line. ${ }^{86}$ Yet, majority of healthcare financing is out-of-pocket payments. ${ }^{87}$ User fee is a major barrier to healthcare access, especially for vulnerable populations like pregnant women ${ }^{88}$ and has implications for maternal health. ${ }^{89}$ The findings showed that the higher the wealth of the woman, the more likely she is to use maternal healthcare. This could be accredited to the fact that women with higher income may have the purchasing power to afford the cost and other expenses that come with consultation, purchasing of recommended medication and transportation cost to the health facility, while women with limited financial resources may have difficulties paying for the cost of healthcare. ${ }^{6190}$

We found that the place and region of residence of women is significantly related to ANC, SBA and PNC utilisation. This implies that physical proximity to a health facility is an important factor in maternal healthcare utilisation in Mali. This finding is consistent with previous studies that also reported an association between place of residence and maternal healthcare utilisation. ${ }^{91-93}$ The finding could be explained by the fact that women residing in urban areas have physical accessibility to health facilities that are predominantly available than women in the rural setting where health facilities are 
scarce, hence accessibility to healthcare may be much easier for the urban dwellers than the rural dwellers, thereby increasing the probability of women in the urban settings using maternal health compared with her rural counterparts. The remote distance together with bad road networks from rural settings to the health facility alongside transportation problems could discourage rural dwellers from using maternal healthcare. In Mali, the majority of government-owned health facilities are located in the urban areas or cities and far away from rural settlements, making maternal healthcare utilisation difficult for rural residents due to the cost and time of getting to the facility. ${ }^{94-99}$ There is, thus, inequity in distribution of development and infrastructure, including in healthcare facilities. For instance, being the national capital, Bamako has access to more development and healthcare infrastructure compared with the rest of the country. Thus, it is expected that barriers such as distance to health facilities, unavailability of care and long time in getting to facilities would be limited.

A major limitation of this study is the use of the secondary data from DHS which relied on verbal reports from participants. This has the tendency of recall bias and under-reporting or over-reporting of some behaviours. Nevertheless, efforts were made during the data collection process to encourage participants to provide honest responses. Again, we did not have any control over cleaning and ensuring internal consistency in the data.

\section{CONCLUSION}

Maternal healthcare utilisation by women plays a momentous role in reducing maternal complications which lead to maternal mortality. However, the overall prevalence of maternal healthcare utilisation among women in reproductive age in Mali was low, specifically ANC4 + and PNC. Various individual and contextual factors predict maternal service utilisation in Mali. Predominant among these is availability or proximity to a health facility, as well as ownership of healthcare insurance. Therefore, it is imperative for the government of Mali to increase the availability and accessibility to healthcare facilities across the country through improved health infrastructure and workforce strengthening to help achieve the target of SDG 3.4 of reducing maternal morality to less than 70 deaths per 100000 live births by 2030 .

Despite the important findings made in this research, the study was not able to assess other user factors such as cost and quality of care at the health facility as they are not covered in the DHS despite their importance. Further studies could also focus on complications of pregnancy and delivery using another methodology as these are also not covered by DHS.

\footnotetext{
Author affiliations

${ }^{1}$ Lincoln International Institute for Rural Health, University of Lincoln, Lincoln, UK

${ }^{2}$ Global South Health Research and Services, Amsterdam, The Netherlands
}

${ }^{3}$ Epidemiology and Biostatistics, School of Public Health, University of Health and Allied Sciences, Hohoe, Ghana

${ }^{4}$ United Nations Population Fund, Lusaka, Zambia

${ }^{5}$ Population and Behavioural Sciences, School of Public Health, University of Health and Allied Sciences, Hohoe, Ghana

${ }^{6}$ United Nations Population Fund, Kinshasa, Congo

Twitter Hubert Amu @hubert_amu

Acknowledgements The authors thank the DHS for permission to access and use Mali's 2018 DHS data set.

Contributors LEB: Guarantor, Conception and design, interpretation of data and revision; RGA: Data acquisition and analysis and interpretation; GM: Conception and design, drafting; HA: Conception and design, interpretation of data, drafting and revision; RKD: Design, drafting and revision; FIS: Design, drafting and revision; EJK: Conception and design, and interpretation of data.

Funding The authors have not declared a specific grant for this research from any funding agency in the public, commercial or not-for-profit sectors.

Competing interests None declared.

Patient consent for publication Not applicable.

Provenance and peer review Not commissioned; externally peer reviewed.

Data availability statement Data are available in a public, open access repository. Data are freely available to the public on the DHS website.

Supplemental material This content has been supplied by the author(s). It has not been vetted by BMJ Publishing Group Limited (BMJ) and may not have been peer-reviewed. Any opinions or recommendations discussed are solely those of the author(s) and are not endorsed by BMJ. BMJ disclaims all liability and responsibility arising from any reliance placed on the content. Where the content includes any translated material, BMJ does not warrant the accuracy and reliability of the translations (including but not limited to local regulations, clinical guidelines, terminology, drug names and drug dosages), and is not responsible for any error and/or omissions arising from translation and adaptation or otherwise.

Open access This is an open access article distributed in accordance with the Creative Commons Attribution Non Commercial (CC BY-NC 4.0) license, which permits others to distribute, remix, adapt, build upon this work non-commercially, and license their derivative works on different terms, provided the original work is properly cited, appropriate credit is given, any changes made indicated, and the use is non-commercial. See: http://creativecommons.org/licenses/by-nc/4.0/.

\section{ORCID iDs}

Richard Gyan Aboagye http://orcid.org/0000-0002-3498-2909

Hubert Amu http://orcid.org/0000-0003-0218-3843

Farrukh Ishaque Saah http://orcid.org/0000-0001-8395-8369

\section{REFERENCES}

1 World Health Organization. Maternal mortality. Fact-sheet. World Health Organization, 2019a. Available: https://www.who.int/newsroom/fact-sheets/detail/maternal-mortality

2 Banke-Thomas OE, Banke-Thomas AO, Ameh CA. Factors influencing utilisation of maternal health services by adolescent mothers in Low-and middle-income countries: a systematic review. BMC Pregnancy Childbirth 2017;17:1-4.

3 Nove A, Matthews Z, Neal S, et al. Maternal mortality in adolescents compared with women of other ages: evidence from 144 countries. Lancet Glob Health 2014;2:e155-64.

4 World Health Organization. Trends in maternal mortality 2000 to 2017 estimates by who, UNICEF, UNFPA, world bank group and the United nations population division. Geneva: World Health Organization, 2019.

5 United Nations. Transforming our world: the 2030 agenda for sustainable development. New York: United Nations, 2015.

6 United Nations. The sustainable development goals report. United Nations, 2019.

7 Haruna U, Dandeebo G, Galaa SZ. Improving access and utilization of maternal healthcare services through focused antenatal care in rural Ghana: a qualitative study. Adv Public Health 2019;2019:1-11.

8 Girum T, Wasie A. Correlates of maternal mortality in developing countries: an ecological study in 82 countries. Maternal Health, Neonatology and Perinatology 2017;3:1-6. 
9 World Health Organization. Maternal mortality fact sheet No. 348. World Health Organization, 2015.

10 Borghi J, Hanson K, Acquah CA, et al. Costs of near-miss obstetric complications for women and their families in Benin and Ghana. Health Policy Plan 2003;18:383-90.

11 Sanogo N'doh Ashken, Yaya S. Wealth status, health insurance, and maternal health care utilization in Africa: evidence from Gabon. Biomed Res Int 2020;2020:4036830.

12 Yaya S, Da F, Wang R, et al. Maternal healthcare insurance ownership and service utilisation in Ghana: analysis of Ghana demographic and health survey. PLoS One 2019;14:e0214841.

13 Twum P, Qi J, Aurelie KK, et al. Effectiveness of a free maternal healthcare programme under the National health insurance scheme on skilled care: evidence from a cross-sectional study in two districts in Ghana. BMJ Open 2018;8:e022614.

14 Ataullahjan A, Gaffey MF, Tounkara M, et al. C'est vraiment compliqué: a case study on the delivery of maternal and child health and nutrition interventions in the conflict-affected regions of Mali. Confl Health 2020;14:36.

15 Coulibaly P, Schantz C, Traoré B, et al. In the era of humanitarian crisis, young women continue to die in childbirth in Mali. Confl Health 2021:15:1-4.

16 Tounkara M, Sangho O, Beebe M. Geographic access and maternal health services utilization in Sélingué health district, Mali. Research Square, 2020.

17 Institut National de la Statistique (INSTAT), Cellule de Planication et de Statistique Secteur SantéDéveloppement Social et Promotion de la Famille (CPS/SS-DS-PF) et ICF. Enquête Démographique et de Santé Au Mali 2018. Bamako, Mali et Rockville, 2019. Available: https://dhsprogram.com/publications/publication-FR358-DHS-FinalReports.cfm

18 Aa I, Grove MA, Haugsjå AH, et al. High maternal mortality estimated by the sisterhood method in a rural area of Mali. BMC Pregnancy Childbirth 2011:11:1-6.

19 Çalıșkan Z, Kılıç D, Öztürk S, et al. Equity in maternal health care service utilization: a systematic review for developing countries. Int $J$ Public Health 2015:60:815-25.

20 El-Khoury M, Gandaho T, Arur A, et al. Improving access to life saving maternal health services: the effects of removing user fees for caesareans in Mali. Health Syst 2011;20:20.

21 Ministère de la Santé du Mali. Décret $n^{\circ}$ 05-350/P-RM du 04 août 2005 - Relatif la prise en charge gratuité de la césarienne. [Internet], 2005. Available: http://mail.cnom.sante.gov.ml/index.php?option= com content\&task $=$ view\&id $=406 \&$ Itemid $=87$

22 Adepoju P. Mali announces far-reaching health reform. Lancet 2019;393:1192.

23 Ministère de la Santé et de l'Hygiène Publique. New presidential initiative launches in Mali: strikes at the epicenter of the global maternal and child mortality crisis, 2019. Available: https://www. musohealth.org/wp-content/uploads/2019/02/PathbreakingPresidential-Healthcare-Reform-Mali.pdf

24 Mturi AJ, Gaearwe L. Gender differences in sexual behaviour amongst university students in Mahikeng, South Africa. African Population Studies 2014;28:526-37.

25 Peters DH, Garg A, Bloom G, et al. Poverty and access to health care in developing countries. Ann N Y Acad Sci 2008;1136:161-71.

26 Alhassan RK, Owusu-Agyei S, Ansah EK, et al. Trends and correlates of maternal, newborn and child health services utilization in primary healthcare facilities: an explorative ecological study using DHIMSII data from one district in the Volta region of Ghana. BMC Pregnancy Childbirth 2020;20:1-5.

27 Corsi DJ, Neuman M, Finlay JE, et al. Demographic and health surveys: a profile. Int J Epidemiol 2012;41:1602-13.

28 Aliaga A, Ruilin R. Cluster optimal sample size for demographic and health surveys. Paper presented at the 7th International Conference on Teaching Statistics-ICOTS, ORC Macro, 2006.

29 [dataset] Institut National de la Statistique (INSTAT), Cellule de Planification et de Statistique Secteur Santé-Développement Social et Promotion de la Famille (CPS/SS-DS-PF), ICF. Data from: Enquête Démographique et de Santé Au Mali 2018. DHS, 2019. Available: https://dhsprogram.com/data/available-datasets.cfm

30 von Elm E, Altman DG, Egger M, et al. The strengthening the reporting of observational studies in epidemiology (STROBE) statement: guidelines for reporting observational studies. Int J Surg 2014:12:1495-9.

31 World Bank. Population, total - Mali. Available: https://data. worldbank.org/indicator/SP.POP.TOTL?locations=ML

32 Frontline Health Project. The community health system in Mali: overview, 2020. Available: https://www.popcouncil.org/uploads/pdfs/ 2020RH_CommunityHealthSystemMali.pdf
33 USAID. Mali: global health, 2021. Available: https://www.usaid.gov/ mali/global-health

34 Ahinkorah BO, Seidu A-A, Agbaglo E, et al. Determinants of antenatal care and skilled birth attendance services utilization among childbearing women in guinea: evidence from the 2018 guinea demographic and health survey data. BMC Pregnancy Childbirth 2021;21:2.

35 Singh P, Singh KK, Singh P. Maternal health care service utilization among young married women in India, 1992-2016: trends and determinants. BMC Pregnancy Childbirth 2021;21:1-13.

36 Yaya S, Zegeye B, Ahinkorah BO, et al. Predictors of skilled birth attendance among married women in Cameroon: further analysis of 2018 Cameroon demographic and health survey. Reprod Health 2021;18:1-12.

37 Rai RK, Singh PK, Singh L. Utilization of maternal health care services among married adolescent women: insights from the Nigeria demographic and health survey, 2008. Womens Health Issues 2012;22:e407-14.

38 Tiruneh FN, Chuang K-Y, Chuang Y-C. Women's autonomy and maternal healthcare service utilization in Ethiopia. BMC Health Serv Res 2017;17:718

39 Tarekegn SM, Lieberman LS, Giedraitis V. Determinants of maternal health service utilization in Ethiopia: analysis of the 2011 Ethiopian demographic and health survey. BMC Pregnancy Childbirth 2014:14:1-3.

40 Institut National de la Statistique (INSTAT) and ICF. 2018 demographic and health survey key findings. Rockville, Maryland, USA: INSTAT and ICF, 2019.

41 Owusu SS. Factors associated with antenatal care service utilization among women with children under five years in Sunyani Municipality, Ghana. medRxiv 2021.

42 Tessema ZT, Minyihun A. Utilization and determinants of antenatal care visits in East African countries: a multicountry analysis of demographic and health surveys. Adv Public Health 2021;2021:1-9.

43 Tessema ZT, Teshale AB, Tesema GA, et al. Determinants of completing recommended antenatal care utilization in sub-Saharan from 2006 to 2018: evidence from 36 countries using demographic and health surveys. BMC Pregnancy Childbirth 2021;21:1-2.

44 Ganle JK, Kombet ML, Baatiema L. Factors influencing the use of supervised delivery services in Garu-Tempane district, Ghana. BMC Pregnancy Childbirth 2019:19:141.

45 Appiah F, Salihu T, Fenteng JOD, et al. Postnatal care utilisation among women in rural Ghana: analysis of 2014 Ghana demographic and health survey. BMC Pregnancy Childbirth 2021;21:26.

46 Abota TL, Atenafu NT, TadeleAtenafu N. Postnatal care utilization and associated factors among married women in Benchi-Maji zone, Southwest Ethiopia: a community based cross-sectional study. Ethiop J Health Sci 2018;28:267-76.

47 Tessema ZT, Yazachew L, Tesema GA, et al. Determinants of postnatal care utilization in sub-Saharan Africa: a meta and multilevel analysis of data from 36 sub-Saharan countries. Ital J Pediatr 2020;46:175

48 Ameyaw EK, Dickson KS. Skilled birth attendance in Sierra Leone, niger, and Mali: analysis of demographic and health surveys. BMC Public Health 2020;20:164.

49 Tunçalp Ö, Pena-Rosas JP, Lawrie T, et al. Who recommendations on antenatal care for a positive pregnancy experience-going beyond survival. BJOG: Int J Obstet Gy 2017;124:860-2.

50 World Health Organization. Who recommended interventions for improving maternal and newborn health. WHO, 2009.

51 World Health Organization. Who antenatal care randomized trial: manual for the implementation of the new model, who document WHO/RHR/01.30. Geneva: WHO, 2002.

52 Mchenga M, Burger R, von Fintel D. Examining the impact of who's focused antenatal care policy on early access, underutilisation and quality of antenatal care services in Malawi: a retrospective study. BMC Health Serv Res 2019;19:295.

53 The Borgen Project. Maternal and child health in Mali, 2017. Available: https://borgenproject.org/maternal-and-child-health-inmali/

54 Cellule de Planification et de Statistique, Institut National de la Statistique, Centre d'Études et d'Information Statistiques, ICF International. In: Mali Enquête Démographique et de Santé (EDSM V) 2012-2013;2014. Available: http://dhsprogram.com/pubs/pdf/FR286/ FR286.pdf

55 Nyongesa C, Xu X, Hall JJ, et al. Factors influencing choice of skilled birth attendance at ANC: evidence from the Kenya demographic health survey. BMC Pregnancy Childbirth 2018;18:88.

56 Atuoye KN, Amoyaw JA, Kuuire VZ, et al. Utilisation of skilled birth attendants over time in Nigeria and Malawi. Glob Public Health 2017:12:728-43. 
57 Alemayehu M, Mekonnen W. The prevalence of skilled birth attendant utilization and its correlates in North West Ethiopia. Biomed Res Int 2015;2015:436938-8.

58 Adde KS, Dickson KS, Amu H. Prevalence and determinants of the place of delivery among reproductive age women in sub-Saharan Africa. PLoS One 2020;15:e0244875.

59 Dickson KS, Amu H. Determinants of skilled birth attendance in the Northern parts of Ghana. Advances in Public Health 2017;2017:1-8.

60 Darteh EKM, Doku DT, Esia-Donkoh K. Reproductive health decision making among Ghanaian women. Reprod Health 2014;11:1-8.

61 Nuamah GB, Agyei-Baffour P, Mensah KA, et al. Access and utilization of maternal healthcare in a rural district in the forest belt of Ghana. BMC Pregnancy Childbirth 2019;19:6.

62 Kibusi SM, Sunguya BF, Kimunai E, et al. Health insurance is important in improving maternal health service utilization in Tanzaniaanalysis of the 2011/2012 Tanzania HIV/AIDS and malaria indicator survey. BMC Health Serv Res 2018;18:112.

63 Fernandes P, Odusina EK, Ahinkorah BO, et al. Health insurance coverage and maternal healthcare services utilization in Jordan: evidence from the 2017-18 Jordan demographic and health survey. Arch Public Health 2021;79:81.

64 Amu H, Seidu A-A, Agbaglo E, et al. Mixed effects analysis of factors associated with health insurance coverage among women in subSaharan Africa. PLoS One 2021;16:e0248411.

65 World Health Organization and The World Bank. Tracking universal health coverage: 2017 global monitoring report. Switzerland: World Health Organization and The World Bank, 2017. http://pubdocs. worldbank.org/en/193371513169798347/2017-global-monitoringreport.pdf

66 Kanya L, Obare F, Warren C, et al. Safe motherhood voucher programme coverage of health facility deliveries among poor women in south-western Uganda. Health Policy Plan 2014;29 Suppl 1:i4-11.

67 Scheil-Adlung X, Carrin G, Juetting J. What is the impact of social health protection on access to health care, health expenditure and impoverishment? A comparative analysis of three African countries. International Labour Office, 2006.

68 Otieno PO, Asiki G. Making universal health coverage effective in low-and middle-income countries: a blueprint for health sector reforms. healthcare Access-regional overviews 2020.

69 Fatema K, Lariscy JT. Mass media exposure and maternal healthcare utilization in South Asia. SSM Popul Health 2020;11:100614.

70 Wang Y, Etowa J, Ghose B, et al. Association between mass media use and maternal healthcare service utilisation in Malawi. $J$ Multidiscip Healthc 2021:14:1159.

71 Zamawe COF, Banda M, Dube AN. The impact of a community driven mass media campaign on the utilisation of maternal health care services in rural Malawi. BMC Pregnancy Childbirth 2016;16:1-8.

72 Acharya D, Khanal V, Singh JK, et al. Impact of mass media on the utilization of antenatal care services among women of rural community in Nepal. BMC Res Notes 2015;8:1-6.

73 Khan MN, Kumar P, Rahman MM, et al. Inequalities in utilization of maternal reproductive health care services in urban Bangladesh: a population-based study. Sage Open 2020;10:215824402091439.

74 Mulenga JN, Bwalya BB, Gebremeskel Y. Demographic and socioeconomic determinants of maternal health insurance coverage in Zambia. Epidemiology, Biostatistics and Public Health 2017;14.

75 Peng YK, Hight-Laukaran V, Peterson AE, et al. Maternal nutritional status is inversely associated with lactational amenorrhea in subSaharan Africa: results from demographic and health surveys II and III. J Nutr 1998;128:1672-80.

76 Yaya S, Bishwajit G. Predictors of institutional delivery service utilization among women of reproductive age in Gambia: a crosssectional analysis. BMC Pregnancy Childbirth 2020;20:1-0.
77 Dapaah JM, Nachinaab JO. Sociocultural determinants of the utilization of maternal health care services in the Tallensi district in the upper East region of Ghana. Adv Public Health 2019;2019:1-11.

78 Deepak C, Jauhari N J, Dhungana H D. A study on utilization of maternal health services and factors influencing the utilization in urban slums of Lucknow. Int J Med Public Health 2018;8:77-81.

79 Ndao-Brumblay SK, Mbaruku G, Kruk ME. Parity and institutional delivery in rural Tanzania: a multilevel analysis and policy implications. Health Policy Plan 2013;28:647-57.

80 Fotso JC, Ezeh A, Oronje R. Provision and use of maternal health services among urban poor women in Kenya: what do we know and what can we do? J Urban Health 2008;85:428-42.

81 Chakraborty N, Islam MA, Chowdhury RI, et al. Determinants of the use of maternal health services in rural Bangladesh. Health Promot Int 2003;18:327-37.

82 Nuamah GB, Agyei-Baffour P, Akohene KM, et al. Incentives to yield to obstetric referrals in deprived areas of Amansie West district in the Ashanti region, Ghana. Int J Equity Health 2016;15:117.

83 Arthur E. Wealth and antenatal care use: implications for maternal health care utilisation in Ghana. Health Econ Rev 2012;2:1-8.

84 Aseweh Abor P, Abekah-Nkrumah G, Sakyi K, et al. The socioeconomic determinants of maternal health care utilization in Ghana. Int J Soc Econ 2011;38:628-48.

85 Vecino-Ortiz Al. Determinants of demand for antenatal care in Colombia. Health Policy 2008;86:363-72.

86 USAID. Mali: country profile. Bamako, 2021. Available: https://www. usaid.gov/sites/defaul/files/documents/Mali_profile_October_21_ Final.pdf

87 WHO Africa Region. State of health financing in the African region. Brazzaville, Congo, 2013. Available: https://www.afro.who.int/sites/ defaul/files/2017-06/state-of-health-financing-afro.pdf

88 Lagarde M, Palmer $\mathrm{N}$. The impact of user fees on health service utilization in low- and middle-income countries: how strong is the evidence? Bull World Health Organ 2008:86:839-48.

89 Koblinsky M, Moyer CA, Calvert C, et al. Quality maternity care for every woman, everywhere: a call to action. Lancet 2016;388:2307-20.

90 Yaya S, Bishwajit G, Shah V. Wealth, education and urban-rural inequality and maternal healthcare service usage in Malawi. BMJ Glob Health 2016;1:e000085.

91 Abor PA, Abekah-Nkrumah G. The socio-economic determinants of maternal health care utilization in Ghana. African economic research Consortium, 2009

92 Celik Y, Hotchkiss DR. The socio-economic determinants of maternal health care utilization in turkey. Soc Sci Med 2000;50:1797-806.

93 Navaneetham K, Dharmalingam A. Utilization of maternal health care services in southern India. Soc Sci Med 2002;55:1849-69.

94 Islam MA, Barna SD. Concise title: maternal health service utilization. Clin Epidemiol Glob Health 2020;8:1236-41.

95 Rashid M, Antai D. Socioeconomic position as a determinant of maternal healthcare utilization: a population-based study in Namibia. $J$ Res Health Sci 2014;14:187-92.

96 Zelalem Ayele D, Belayihun B, Teji K, et al. Factors affecting utilization of maternal health care services in Kombolcha district, eastern Hararghe zone, Oromia regional state, eastern Ethiopia. Int Sch Res Notices 2014;2014:917058.

97 Shiferaw S, Spigt M, Godefrooij M, et al. Why do women prefer home births in Ethiopia? BMC Pregnancy Childbirth 2013;13:1.

98 Say L, Raine R. A systematic review of inequalities in the use of maternal health care in developing countries: examining the scale of the problem and the importance of context. Bull World Health Organ 2007;85:812-9.

99 Harang M. Système de soins et croissance urbaine dans une ville en mutation. Le Cas de Ouagadougou (Burkina Faso). PHD thesis in geography. Paris: Université Paris X Nanterre, 2007. 